\title{
Allemagne: La psychothérapie systémique doit être financée par les caisses
}

\section{Peter Schulthess}

Le 22 novembre 2018, dix ans après la reconnaissance de la psychothérapie systémique par le Conseil consultatif scientifique sur la psychothérapie, le Comité mixte fédéral (G-BA) a confirmé l'utilité et la nécessité médicale de la thérapie systémique chez l'adulte, jetant ainsi les bases sur le fait que la thérapie systémique doit être financée comme une prestation dassurance de la Caisse d’assurance maladie légale à lavenir. Le G-BA note un avantage dans cinq domaines d'application.
Selon les informations du ministère fédéral de la santé, la procédure dévaluation doit être achevée d'ici le 2019 mars. La thérapie systémique sera alors reconnue comme la quatrième directive pour le traitement des troubles mentaux.

Peter Schulthess est membre du Conseil d'administration de l'ASP et le représente avec Gabriela Rüttimann au sein de l'EAP. Il est également président du SARC au sein de l'EAP.

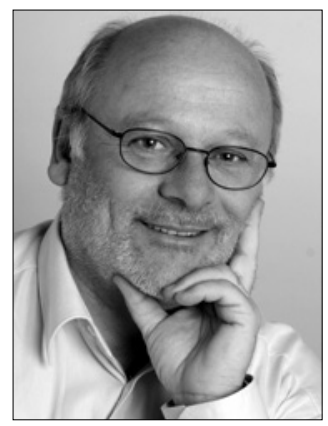

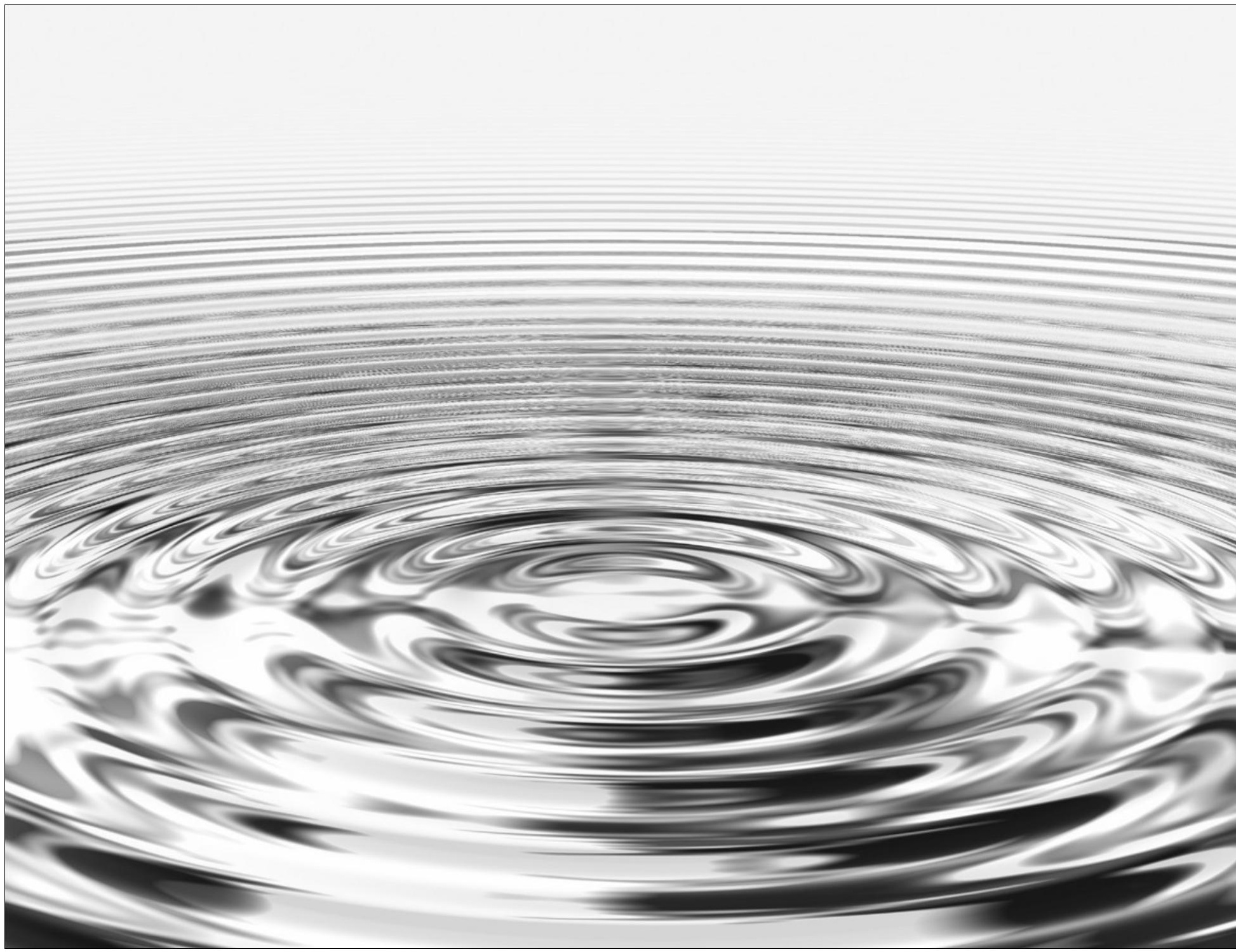

